\title{
Microbial Properties of Probiotic Fermented Milk Supplemented with Ginseng Extracts
}

\author{
Sharareh Hekmat ${ }^{1,2^{*}}$, Adriana Cimo ${ }^{1}$, Mohammad Soltani ${ }^{1}$, Edmund Lui ${ }^{3}$, Gregor Reid $^{2}$ \\ ${ }^{1}$ Division of Food and Nutritional Sciences, Brescia University College, Western University, London, Canada; ${ }^{2}$ Canadian Research \\ and Development Centre for Probiotics, St. Joseph's Hospital, London, Canada; ${ }^{3}$ Department of Physiology and Pharmacology, \\ Schulich School of Medicine and Dentistry, Western University, London, Canada. \\ Email: "hekmat@uwo.ca
}

Received February $10^{\text {th }}, 2013$; revised March $8^{\text {th }}, 2013$; accepted March $16^{\text {th }}, 2013$

Copyright (C) 2013 Sharareh Hekmat et al. This is an open access article distributed under the Creative Commons Attribution License, which permits unrestricted use, distribution, and reproduction in any medium, provided the original work is properly cited.

\begin{abstract}
The therapeutic properties of Lactobacillus rhamnosus GR-1 and ginseng extracts have been well documented. The objective of this study was to measure growth and survival of L. rhamnosus GR-1 in milk fortified with ginseng extracts during storage period of 28 days. Five formulations of milk ( $1 \%$ fat) were prepared. Two samples were fortified with alcoholic ginseng extract (AGE: $150 \mu \mathrm{g} / \mathrm{mL}$, AGE: $500 \mu \mathrm{g} / \mathrm{mL}$ ) and the other two samples were fortified with aqueous ginseng extract (QGE: $150 \mu \mathrm{g} / \mathrm{mL}$, QGE: $500 \mu \mathrm{g} / \mathrm{ml}$ ) and one with no ginseng extract (C). The mixtures were autoclaved for $15 \mathrm{~min}$, cooled to $37^{\circ} \mathrm{C}$ and inoculated with $1 \%$ starter culture. The samples were then incubated anaerobically at $37^{\circ} \mathrm{C}$ overnight. Selective MRS agar containing $0.015 \mathrm{~g} / \mathrm{L}$ fusidic acid was used to enumerate L. rhamnosus GR-1 after 1, 14, and $28 \mathrm{~d}$ storage at $4^{\circ} \mathrm{C}$. All ginseng-fortified samples supported the growth and survival of L. rhamnosus GR-1, as viable counts were detected at each measurement point throughout the $28 \mathrm{~d}$ storage period. After $1 \mathrm{~d}$ of storage, total colony counts for L. rhamnosus GR-1 in AGE: $150 \mu \mathrm{g} / \mathrm{mL}$ and AGE: $500 \mu \mathrm{g} / \mathrm{mL}$ were $1.3 \times 10^{9}$ and $1.4 \times$ $10^{9} \mathrm{CFU} / \mathrm{mL}$, respectively; probiotic counts in QGE $150 \mu \mathrm{g} / \mathrm{mL}$ and QGE: $500 \mu \mathrm{g} / \mathrm{mL}$ were $1.5 \times 10^{9}$ and $1.4 \times 10^{9}$ $\mathrm{CFU} / \mathrm{mL}$, respectively. Additionally, L. rhamnosus GR-1 viability remained stable throughout the 28 days storage period, as no significant decrease $(\mathrm{p}<0.05)$ in total colony counts were detected. The results indicate that $L$. rhamnosus GR-1 can remain viable in presence of ginseng extracts during storage period and there is potential for incorporating ginseng extracts in other probiotic dairy products.
\end{abstract}

Keywords: Yogurt; Ginseng; Probiotic

\section{Introduction}

Research suggests that ginseng consumption is able to prevent and manage chronic diseases such as atherosclerotic plaque formation [1], and diabetes induced kidney damage $[2,3]$. There are many chemical constituents within ginseng extracts, including ginsenosides, glycans, oligosaccharides, polysaccharides, peptides, fatty acids, and polyacetylenic alcohols [3]. The pharmacological components believed to produce the majority of possible health benefits are ginsenosides [1,4-6]. Structurally, ginsenosides consist of 4-trans ring steroidal saponins with a variety of sugar moieties attached [6]. American ginseng mostly contains ginsenosides $\mathrm{Rb} 1, \mathrm{Rb} 2, \mathrm{Rc}$, and $\mathrm{Rd}$, which are characterized by the presence of 20(S)-protopanaxadiol as an aglycon; and ginsenosides $\operatorname{Rg} 1$ and

${ }^{*}$ Corresponding author.
Re, which contain 20(S)-protopanaxatriol as an aglycon $[2,6]$. It has been suggested that ginsenosides are able to enter the cell and initiate intracellular mechanisms [6,7]. However, their large molecular size and high polarity prevent ginsenoside absorption within the intestinal tract [8]. Ginsenosides become able to enter circulation through the intestinal microflora, as these microorganisms conduct a series of reactions that convert ginsenosides into compounds that can be absorbed [8-10]. It is postulated that these final compounds may be responsible for the health benefits associated with ginseng $[8,10]$.

Given that intestinal microflora play a significant role in the digestion and absorption of ginsenosides, it is important to consider that the health of gut microflora can be hindered by daily stress, changes in eating habits, and use of oral medications such as antibiotics [11-13]. Therefore, it may be beneficial for individuals supplementing 
their diet with ginseng to also maintain their gut health through the use of probiotics, as consuming some bacterial strains can promote the health of existing gut microflora $[11,14]$.

Various strains of lactic acid bacteria that meet the criteria developed by the United Nations and World Health Organization Expert Panel are considered probiotic [15]. Two such species include Lactobacillus rhamnosus GR-1 and Lactobacillus reuteri (previously fermentus) RC-14. They are bile resistant, survive passage through and colonize the gastrointestinal tract, and are able to relieve diarrhea with flatulence without causing adverse systemic immune or inflammatory outcomes [16-18]. This combination of bacteria can also colonize the vagina, preventing the presence of yeast and Escherichia coli, thus reducing the possibility of bacterial vaginosis, yeast vaginitis and urinary tract infections $[16$, 19-21].

Milk and yogurt products are successful vehicles to deliver probiotic microorganisms combined with herbal products to consumers [22-24]. However, in order to ensure that a novel product is probiotic, it must contain at least $10^{6}-10^{7}$ colony forming units $(\mathrm{CFU}) / \mathrm{mL}$, which is the minimum amount required to produce health benefits on the host [20,22,25-27]. Given that reduced $\mathrm{pH}$ can decrease probiotic bacteria viability, and both yogurt starter cultures and some herbal and plant-based additives can potentially facilitate a drop in $\mathrm{pH}$, yogurt starter cultures were not added in this experiment [22,27]. The objective of this study was to monitor growth and survival of $L$. rhamnosus GR-1 in milk containing both aqueous ginseng extract (QGE) and alcoholic ginseng extract (AQE) during a 28-day storage period.

\section{Material and Methods}

\subsection{Culture Preparation}

Production of the ginseng fortified probiotic milk required preparation of a probiotic bacteria stock that was generated every 14 days. This involved adding L. rhamnosus GR-1 (Urex, Biotech Inc., London, Ontario, Canada) to sterilized (autoclaved $15 \mathrm{psi}$ at $121^{\circ} \mathrm{C}$ for $15 \mathrm{~min}$.) de Man, Rogosa and Sharpe (MRS) broth at a $10 \%$ by weight concentration. The mixture was then incubated with a BBL GasPak ${ }^{\mathrm{TM}}$ system (Becton Dickinson \& Co., Sparks, MD, USA) in order to create anaerobic conditions at $37.5^{\circ} \mathrm{C}$ for 16 hours. This culture was then routinely generated in MRS broth every 14 days.

\subsection{Ginseng Extract Preparation}

The Ontario Ginseng Growers Association provided fouryear-old Native American ginseng roots from five different farms in Ontario, Canada, harvested in 2007. Azike et al. [28] have documented detailed methods regarding preparation of aqueous and alcoholic ginseng extracts. Naturex (New Jersey, USA) conducted the aqueous and alcoholic extraction from dried ginseng root samples. This process involved grinding ginseng roots and soaking $4 \mathrm{~kg}$ for three five hour periods in $16 \mathrm{~L}$ of either water or ethanol/water $(75 / 25, \mathrm{v} / \mathrm{v})$ solution at $40^{\circ} \mathrm{C}$. Following extraction, excess solvent was removed using a rotary evaporator under vacuum filtration at $45^{\circ} \mathrm{C}$, extracts from each farm were combined, and further concentration was initiated. A water-soluble powder was then formed by lyophilizing the mixture using a freeze dryer (Labonco, USA) at $-55^{\circ} \mathrm{C}$ for $18-20$ hours, vacuum filtering at 10 micron $\mathrm{Hg}$ and crushing the extract using a mortar and pestle.

\subsection{Ginseng Supplemented Probiotic Milk Preparation}

Five formulations of milk were prepared by autoclaving milk ( $1 \%$ fat) at $15 \mathrm{psi}$ for 15 minutes in order to remove any competing microorganisms [26]. Milk was then cooled to $40^{\circ} \mathrm{C}$, following the addition of $150 \mu \mathrm{g} / \mathrm{mL}$ QGE, $500 \mu \mathrm{g} / \mathrm{mL}$ QGE, $150 \mu \mathrm{g} / \mathrm{mL}$ AGE, or $500 \mu \mathrm{g} / \mathrm{mL}$ AGE. One probiotic milk sample was prepared without ginseng extracts $(\mathrm{C})$. Ginseng extract addition followed heat treatment to avoid any possible chemical reactions that could occur when adding ginseng extracts to dairy products, such as oxidation, glycation, and occurrence of the maillard browning reaction [29]. All five mixtures were then inoculated with $1 \%$ concentration of probiotic culture, and then incubated anaerobically at $37^{\circ} \mathrm{C}$ overnight. Two replications of each probiotic milk formulation were prepared.

\subsection{Microbial Analysis}

Viable counts of $L$. rhamnosus GR-1 being stored at $4^{\circ} \mathrm{C}$ was retrieved on days 1,14 and 28. At each measurement point, probiotic milk samples were diluted in autoclaved $0.85 \%$ saline to obtain the concentrations of $10^{-5}, 10^{-6}$, $10^{-7}$, and $10^{-8}$. One tenth milliliter of each dilution was then double plated on agar consisting of Lactobacillus selective MRS and $15 \mathrm{mg} / \mathrm{ml}$ fusidic acid. Plates were then incubated anaerobically at $37.5^{\circ} \mathrm{C}$ for 48 hours, after which viability was quantified by counting the colony forming units on each plate.

\subsection{Statistical Analysis}

Statistical analyses were conducted using the Proc Mixed procedure of SAS Ver 8.02 (SAS Institute, Cary, NC). The experiments were replicated two times in a factorial arrangement. A type 1 error rate of 0.05 was used for all statistical comparisons. Error assumptions of the variance 
analyses (random, homogeneous, normal distribution of error) were confirmed using residual plots and the Shapiro-Wilk normality test. Data where needed were subjected to square root transformation, compared on the transformed scale, and converted back to the original scale for presentation of results. Means were separated according to a Fisher's Protected Least Significant Difference $(\mathrm{LSD})$ test $(\mathrm{p}<0.05)$.

\section{Results}

\section{Microbial Analysis of L. rhamnosus GR-1 in Ginseng Fortified Milk}

The relationship between mean values of colony forming units/mL of probiotic milk containing aqueous ginseng extract (QGE) is presented in Figure 1. It was observed that L. rhamnosus GR-1 viability was unaffected by the presence of QGE during incubation and storage of probiotic milk mixtures, as no statistical significance $(\mathrm{p}>0.05)$ was identified between the three samples at each measurement point. After one day of storage, the probiotic milk control contained $9.5 \times 10^{8} \mathrm{CFU} / \mathrm{mL}$, the sample with $150 \mu \mathrm{g} / \mathrm{mL}$ QGE contained $1.5 \times 10^{9} \mathrm{CFU} / \mathrm{mL}$, and the sample with $500 \mu \mathrm{g} / \mathrm{mL}$ contained $1.4 \times 10^{9} \mathrm{CFU} / \mathrm{mL}$ $(\mathrm{p}>0.05)$. After 14 days of storage, $2.25 \times 10^{9} \mathrm{CFU} / \mathrm{mL}$ was identified in the probiotic control, $1.8 \times 10^{9} \mathrm{CFU} / \mathrm{mL}$ in $150 \mu \mathrm{g} / \mathrm{mL}$ QGE, and $2.75 \times 10^{9} \mathrm{CFU} / \mathrm{mL}$ in the 500 $\mu \mathrm{g} / \mathrm{mL}$ QGE sample. After 28 days of storage, $1.1 \times 10^{9}$ $\mathrm{CFU} / \mathrm{mL}$ was identified in the probiotic control, $1.95 \times$ $10^{9} \mathrm{CFU} / \mathrm{mL}$ in $150 \mu \mathrm{g} / \mathrm{mL}$ QGE, and $1.65 \times 10^{9} \mathrm{CFU} /$ $\mathrm{mL}$ in the $500 \mu \mathrm{g} / \mathrm{mL}$ QGE probiotic milk mixture.

Similarly, the viability of L. rhamnosus GR-1 was not impacted by the presence of alcoholic ginseng extract (AGE) during the incubation and storage period, as there was no significant difference $(p>0.05)$ between mean values of colony forming units/mL of the probiotic milk mixtures. After one day of refrigerated storage the probiotic milk control contained $9.5 \times 10^{8} \mathrm{CFU} / \mathrm{mL}, 150 \mu \mathrm{g} /$ $\mathrm{mL}$ AGE sample contained $1.3 \times 10^{9} \mathrm{CFU} / \mathrm{mL}$, and the milk sample with $500 \mu \mathrm{g} / \mathrm{mL}$ AGE added was found to have $1.4 \times 10^{9} \mathrm{CFU} / \mathrm{mL}$ (Figure 2). After 14 days of storage, $2.25 \times 10^{9} \mathrm{CFU} / \mathrm{mL}$ was identified in the probiotic control, $2.2 \times 10^{9} \mathrm{CFU} / \mathrm{mL}$ in $150 \mu \mathrm{g} / \mathrm{mL}$ AGE, and $2.7 \times 10^{9} \mathrm{CFU} / \mathrm{mL}$ in the $500 \mu \mathrm{g} / \mathrm{mL}$ AGE sample. After 28 days of storage, $1.1 \times 10^{9} \mathrm{CFU} / \mathrm{mL}$ was identified in the probiotic control, $1.8 \times 10^{9} \mathrm{CFU} / \mathrm{mL}$ in $150 \mu \mathrm{g} / \mathrm{mL}$ AGE, and $1.2 \times 10^{9} \mathrm{CFU} / \mathrm{mL}$ in the $500 \mu \mathrm{g} / \mathrm{mL}$ AGE probiotic milk mixture.

\section{Discussion}

Depending on the chemical composition of herbs and other plant-based additives, their addition to probiotic milk products can change $\mathrm{pH}$ and total titratable acid [30-32]. Furthermore, some nutraceutical products have antimicrobial and antioxidant properties [30,33]. The presence of any of these conditions may hinder the growth and viability of probiotic organisms, possibly resulting in milk products containing fewer than $10^{6}$ $10^{7}$ colony forming units $(\mathrm{CFU}) / \mathrm{mL}$ and thus not being able to provide health benefits to the host [20,22,25-27].

Results of this study suggest that viability of L. rhamnosus GR-1 during refrigerated storage is not impacted by the presence of aqueous or alcoholic ginseng extracts, as bacterial counts containing this herb at all measurement points were not significantly different $(p>0.05)$ than the probiotic milk control. These results are comparable to previous research, which reported the viability counts of $L$. rhamnosus GR-1 to be at $2 \times 10^{8} \mathrm{CFU} / \mathrm{mL}$ after one day of storage, and $5 \times 10^{8} \mathrm{CFU} / \mathrm{mL}$ after 28 days of storage in $1 \%$ milk [34]. The probiotic counts in all samples were greater than $10^{7} \mathrm{CFU} / \mathrm{mL}$ during the 28 -

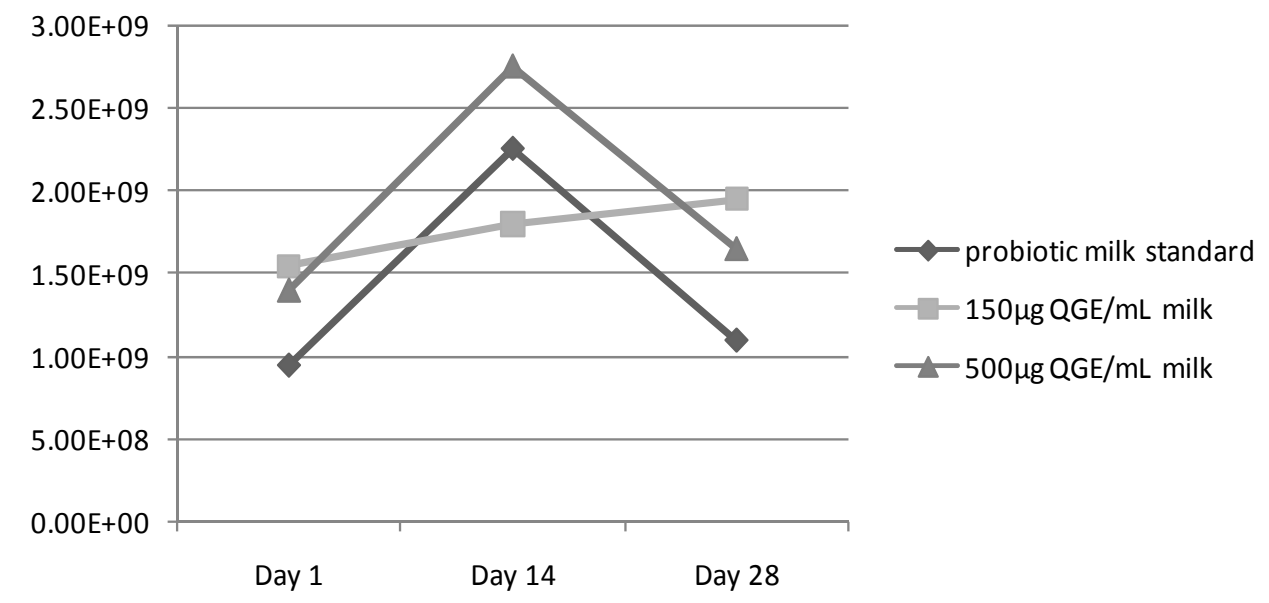

Figure 1. Viability of L. rhamnosus in aqueous ginseng extract (QGE) fortified milk. Assessing L. rhamnosus GR-1 viability in QGE fortified milk over the 28-day shelf life, as compared to standard (probiotic milk containing L. rhamnosus GR-1 without ginseng extract). No statistical significance $(p>0.05)$ was observed. 


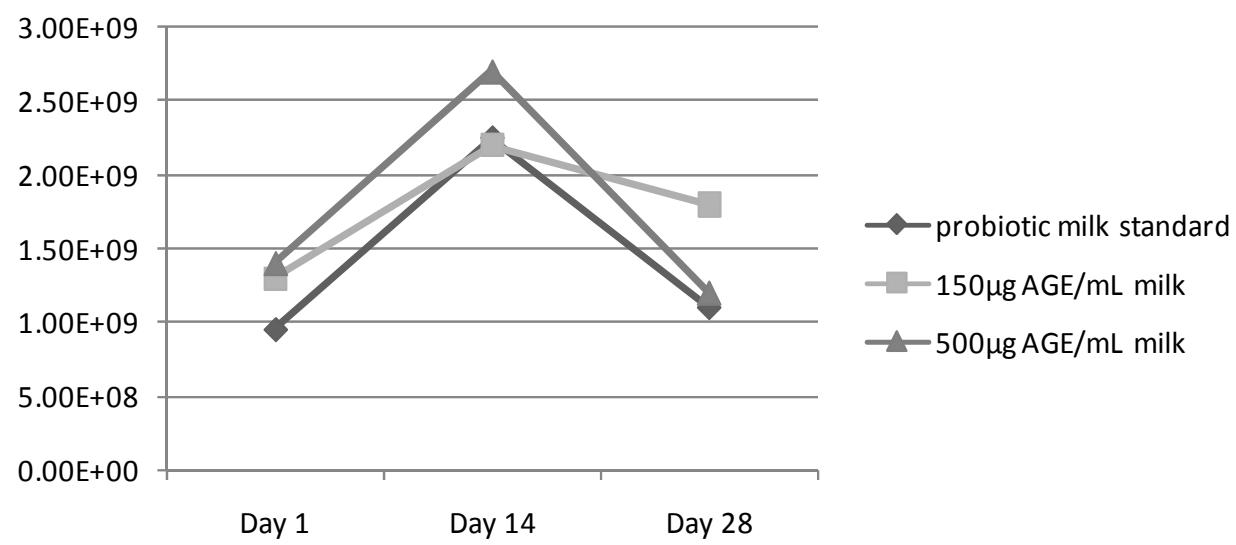

Figure 2. Viability of L. rhamnosus in alcoholic ginseng extract (AGE) fortified milk. Assessing L. rhamnosus GR-1 viability in AGE fortified milk over the 28-day shelf life, as compared to standard (probiotic milk containing L. rhamnosus GR-1 without ginseng extract). No statistical significance $(p>0.05)$ was observed.

day storage period, thus it can be proposed that ginseng extract and L. rhamnosus GR-1 are a suitable combination, as microbial counts are sufficient to exert health benefits on the host.

Observing a neutral presence of ginseng extracts in the probiotic milk medium is an interesting finding. Previous research suggests that ginseng has antioxidant constituents as well as antimicrobial properties against various strains of pathogenic bacteria, thus it would be reasonable to expect reduced probiotic viability [1-3,35]. To our knowledge, no data to support or contradict these findings was present in the literature. However, research has been conducted to investigate the effects of adding herbal compounds with antioxidant and antimicrobial properties on probiotic viability within milk products. Beheshtipour and colleagues [27] added microalgae species Chlorella vulgaris or Arthrospira platensis to yogurt containing probiotic strains Lactobacillus acidophilus LA-5 and Bifidobacterium lactis BB-12. They observed similar antioxidant activity between probiotic yogurts with and without microalgae, and increased viability of both probiotic species containing either $C$. vulgaris or $A$. platensis at each measurement point over the 28-days refrigerated storage period. Haddadin [36] combined either aqueous or alcoholic olive leaf extracts with skim milk containing Bifidobacterium infantis and Lactobacillus acidophilus (strains unspecified). Increased viability of both probiotic strains were observed after $16 \mathrm{~h}$ incubation period for olive extract concentrations below $3.0 \mathrm{mg}$ Catechin Equivalents $/ \mathrm{mL}$, whereas adding $5.0 \mathrm{mg}$ Catechin Equivalents/mL resulted in significantly decreased probiotic viability. The concentration at which olive oil inhibited microbial growth was greater than a previous study where $2 \mathrm{~mL}$ of olive oil exerted bactericidal activity against probiotic microorganisms such as $L$. acidophilus and Bifidobacterium bifidum when placed in bactericidal activity assay [37]. An additional study mixed cinnamon or licorice with probiotic yogurt containing $L$. acidophilus LA-5 and NCMF, B. lactis BB-12, and Lactobacillus casei LC-10 [30]. It was found that both the addition of cinnamon or licorice increased antioxidant activity in the probiotic yogurts and correspondingly, viability of Lactobacillus species was reduced during fermentation and storage; no statistical analysis was completed.

It can therefore be suggested that some herbal and plant-based additives contain favourable characteristics that outweigh their unsuitable properties for probiotic survival in milk products. This may have been the case with the addition of microalgae $C$. vulgaris and A. platensis, as these plants contain nutrients such as exopolysaccharide, adenine, hypoxanthine, free amino acids and essential vitamins and minerals that may have enabled growth and activity of probiotic bacteria [27]. Additionally, the phenolic compounds found in olive leaf extracts may be helpful to probiotic organisms at lower concentrations through decreasing oxidative stress in the yogurt medium and thus creating a favourable environment [36].

A similar concept may apply to the findings observed in this study, as it may be possible that ginseng's prebiotic properties resulted in the viability of $L$. rhamnosus GR-1 being unaffected by the addition of ginseng extracts in the milk medium. Prebiotics are non-digestible components of food that can facilitate the growth and activity of selective bacteria within the large intestine [38]. Generally, prebiotics are carbohydrates with a degree of polymerization of two or more [39]. In accordance with this definition, ginseng extracts are considered to have prebiotic components, as they contain ginsenosides that cannot be absorbed until deglycosylated by microflora $[8,9]$, and nine glucose oligosaccharides with degrees of polymerization between two and 10 [40].

While this study may have established that aqueous and alcoholic ginseng extracts are suitable herbal addi- 
tives for L. rhamnosus GR-1 in milk medium, the need for future research in regard to incorporating ginseng extracts in other probiotic dairy products is warranted, and sensory evaluation would be required to assess consumer response and preferences. Additionally, to date there has been no research done to investigate the impact of fermented milk on the antioxidant properties and ginsenoside stability of ginseng extracts.

\section{Conclusion}

Despite the antimicrobial and antioxidant properties of ginseng, combining aqueous and alcoholic ginseng extracts in milk containing L. rhamnosus GR-1 sustains a favourable medium for the growth and survival of this probiotic species. This indicates there is potential for incorporating ginseng extracts in other probiotic dairy products.

\section{REFERENCES}

[1] J. Li, M. Huang, H. Teoh and R. Y. Man, "Panax Quinquefolium Saponins Protects Low Density Lipoproteins from Oxidation," Life Science, Vol. 64, No. 1, 1999, pp. 53-62. doi:10.1016/S0024-3205(98)00533-5

[2] S. Sen, S. Chen, B. Feng, Y. Wu, E. Lui and S. Chakrabarti, "Preventive Dffects of North American Ginseng (Panax quinquefolium) on Diabetic Nephropathy," Phytomedicine, Vol. 19, No. 19, 2012, pp. 494-505. doi:10.1016/j.phymed.2012.01.001

[3] K. A. Amin, E. M. Awad and M. A. Nagy, "Effects of Panax Quinquefolium on Streptozotocin-Induced Diabetic Rats: Role of C-Peptide, Nitric Oxide and Oxidative Stress," International Journal of Clinical and Experimental Medicine, Vol. 4, No. 2, 2011, pp. 136-147.

[4] H. G. Kim, S. R. Yoo, H. J. Park, N. H. Lee, J. W. Shin, R. Sathyanath, J. H. Cho and C. G. Son, "Antioxidant Effects of Panax Ginseng C. A. Meyer in Healthy Subjects: A Randomized, Placebo-Controlled Clinical Trial," Food and Chemical Toxicology, Vol. 49, No. 9, 2011, pp. 22292235. doi:10.1016/j.fct.2011.06.020

[5] J. Li, T. Ichikawa, Y. Jin, L. J. Hofseth, P. Nagarkatti, M. Nagarkatti, A. Windust and T. Ciu, "An Essential Role of $\mathrm{Nrf} 2$ in American Ginseng-Mediated Anti-Oxidative Actions in Cardiomyocytes," Journal of Ethnopharmacology, Vol. 130, No. 2, 2010, pp. 222-230. doi:10.1016/j.jep.2010.03.040

[6] A. S. Attele, J. A. Wu and C. S. Yuan, "Ginseng Pharmacology: Multiple Constituents and Multiple Actions," Biochemical Pharmacology, Vol. 58, No. 11, 1999, pp. 1685-1693. doi:10.1016/S0006-2952(99)00212-9

[7] C. Buettner, "Systematic Review of the Effects of Ginseng on Cardiovascular Risk Factors," Annals of Pharmacotherapy, Vol. 40, No. 1, 2005, pp. 83-95. doi:10.1345/aph.1G216

[8] B. H. Lee, J. Y. Hyung, S. P. Myeong, K. Bin and E. J. Geun, "Transformation of the Glycosides from Food Materials by Probiotics and Food Microorganisms," Journal of Microbiology and Biotechnology, Vol. 16, No. 4, 2006, pp. 497-504.

[9] H. Hasegawa, "Proof of the Mysterious Efficacy of Ginseng: Basic and Clinical Trials: Metabolic Activation of Ginsenoside: Deglycosylation by Intestinal Bacteria and Esterification with Fatty Acid," Journal of Pharmacological Sciences, Vol. 95, No. 2, 2004, pp. 153-157. doi:10.1254/jphs.FMJ04001X4

[10] E. A. Bae, M. J. Han, E. J. Kim and D. H. Kim, "Transformation of Ginseng Saponins to Ginsenoside Rh 2 by Acids and Human Intestinal Bacteria and Biological Activities of Their Transformants," Archives of Pharmacal Research, Vol. 27, No. 1, 2004, pp. 61-67. doi:10.1007/BF02980048

[11] L. J. Fooks and G. R. Gibson, "Probiotics as Modulators of the Gut Flora," British Journal of Nutrition, Vol. 88, No. S1, 2002, pp. S39-S49. doi:10.1079/BJN20026

[12] J. P. De Bandt, A. J. Waligora-Dupriet and M. J. Butel, "Intestinal Microbiota in Inflammation and Insulin Resistance: Relevance to Humans," Current Opinion in Clinical Nutrition \& Metabolic Care, Vol. 14, No. 4, 2011, pp. 334-340. doi:10.1097/MCO.0b013e328347924a

[13] R. S. Kootte, A. Vrieze, F. Holleman, G. M. DallingaThie, E. G. Zoetendal, W. M. De Vos, A. K. Groen, J. B. L. Hoekstra, E. S. Stroes and M. Nieudorp, "The Therapeutic Potential of Manipulating Gut Microbiota in Obesity and Type 2 Diabetes Mellitus," Diabetes, Obesity and Metabolism, Vol. 14, No. 2, 2012, pp. 112-120. doi:10.1111/j.1463-1326.2011.01483.x

[14] P. B. Shinde, "Probiotic: An Overview for Selection and Evaluation," International Journal of Pharmacy and Pharmaceutical Sciences, Vol. 4, No. 2, 2012, pp. 14-21.

[15] Food and Agriculture Organizations of the United Nations and the World Health Organization, "Guidelines for the Evaluation of Probiotics in Food," 2002. ftp://ftp.fao.org/es/esn/food/wgreport2.pdf

[16] G. Reid, "The Scientific Basis for Probiotic Strains of Lactobacillus," Applied and Environmental Microbiology, Vol. 65, No. 9, 1999, pp. 3763-3766.

[17] G. E. Gardiner, C. Heinemann, M. L. Baroja, A. W. Bruce, D. Beuerman, J. Madrenas and G. Reid, "Oral Administration of the Probiotic Combination Lactobacillus Rhamnosus GR-1 and L. Fermentum RC-14 for Human Intestinal Applications," International Dairy Journal, Vol. 12, No. 2, 2002, pp. 191-196. doi:10.1016/S0958-6946(01)00138-8

[18] K. C. Anukam, E. O. Osazuwa, H. B. Osadolor, A. W. Bruce and G. Reid, "Yogurt Containing Probiotic Lactobacillus Rhamnosus GR-1 and L. reuteri RC-14 Helps Resolve Moderate Diarrhea and Increases CD4 Count in HIV/AIDS Patients," Journal of Clinical Gastroenterology, Vol. 42, No. 3, 2008, pp. 239-243.

[19] G. Reid and J. Burton, "Use of Lactobacillus to Prevent Infection by Pathogenic Bacteria," Microbes and Infection, Vol. 4, No. 3, 2002, pp. 319-324. doi:10.1016/S1286-4579(02)01544-7

[20] G. Reid, D. Beuerman, C. Heinemann and A. W. Bruce, "Probiotic Lactobacillus Dose Required to Restore and Maintain a Normal Vaginal Flora," FEMS Immunology 
and Medical Microbiology, Vol. 32, No. 1, 2001, pp. 3741. doi:10.1111/j.1574-695X.2001.tb00531.x

[21] G. Reid, D. Charbonneau, J. Erb, B. Kochanowski, D. Beuerman, R. Poehner and A. W. Bruce, "Oral Use of Lactobacillus rhamnosus GR-1 and L. fermentum RC-14 Significantly Alters Vaginal Flora: Randomized, PlaceboControlled Trial in 64 Healthy Women," FEMS Immunology and Medical Microbiology, Vol. 35, No. 2, 2003, pp. 131-134. doi:10.1016/S0928-8244(02)00465-0

[22] S. Hekmat, H. Soltani and G. Reid, "Growth and Survival of Lactobacillus reuteri RC-14 and Lactobacillus rhamnosus GR-1 in Yogurt for Use as a Functional Food," Innovative Food Science \& Emerging Technologies, Vol. 10, No. 2, 2009, pp. 269-293.

[23] A. K. Jäger, L. Saaby, D. S. Kudsk, K. C. Witt and P. Mølgaard, "Short Communication: Influence of Pasteurization on the Active Compounds in Medicinal Plants to be Used in Dairy Products," Journal of Dairy Science, Vol. 93, No. 6, 2010, pp. 2351-2353. doi:10.3168/jds.2009-2910

[24] D. Sun-Waterhouse, J. Zhou and S. S. Wadhwa, "Effects of Adding Apple Polyphenols before and after Fermentation on the Properties of Drinking Yoghurt," Food Bioprocess Technology, Vol. 5, No. 7, 2012, pp. 2674-2686. doi:10.1007/s11947-011-0563-1

[25] N. P. Shah, "Probiotic Bacteria: Selective Enumeration and Survival in Dairy Foods," Journal of Dairy Science, Vol. 83, No. 4, 2000, pp. 894-907. doi:10.3168/jds.S0022-0302(00)74953-8

[26] J. Hemsworth, S. Hekmat and G. Reid, "The Development of Micronutrient Supplemented Probiotic Yogurt for People Living with HIV: Laboratory Testing and Sensory Evaluation," Innovative Food Science \& Emerging Technologies, Vol. 12, No. 1, 2011, pp. 79-84. doi:10.1016/i.ifset.2010.11.004

[27] H. Beheshtipour, A. M. Mortazavian, P. Haratian and K. K. Darani, "Effects of Chlorella vulgaris and Arthrospira platensis Addition on Viability of Probiotic Bacteria in Yogurt and Its Biochemical Properties," European Food Research and Technology, Vol. 235, No. 4, 2012, pp. 719728. doi:10.1007/s00217-012-1798-4

[28] C. G. Azike, P. A. Charpentier, J. Hou, H. Pei and E. M. K. Lui, "The Yin and Yang Actions of North American Ginseng Root in Modulating the Immune Function of Macrophages," Chinese Medicine, Vol. 6, No. 27, 2011, pp. 21-32. doi:10.1186/1749-8546-6-21

[29] K. S. Kang, N. Yamabe, H. Y. Kim, T. Okamoto, Y. Sei, T. Yokozawa, "Increase in the Free Radical Scavenging Activities of American Ginseng by Heat Processing and Its Safety Evaluation," Journal of Ethnopharmacology, Vol. 113, No. 1, 2007, pp. 225-232. doi:10.1016/j.jep.2007.05.027

[30] S. Behrad, M. Y. Yusof, K. L. Goh and A. S. Baba, "Manipulation of Probiotics Fermentation of Yogurt by Cin- namon and Licorice: Effects on Yogurt Formation and Inhibition of Helicobacter Pylori Growth in Vitro," World Academy of Science, Engineering and Technology, Vol. 60, 2009, pp. 590-594.

[31] F. C. A. Buriti, I. A. Castro and S. M. I. Saad, "Viability of Lactobacillus acidophilus in Synbiotic Guava Mousses and Its Survival under in Vitro Simulated Gastrointestinal Conditions," International Journal of Food Microbiology, Vol. 137, No. 2-3, 2010, pp. 121-129.

doi:10.1016/j.ijfoodmicro.2009.11.030

[32] G. H. Yang, J. J. Guan, J. S. Wang, H. C. Yin, F. D. Qiao and F. Jia, "Physicochemical and Sensory Characterization of Ginger-Juice Yogurt during Fermentation," Food Science and Biotechnology, Vol. 21, No. 6, 2012, pp. 1541-1548. doi:10.1007/s10068-012-0205-z

[33] A. Duda-Chodak, T. Tarko and M. Statek, "The Effect of Antioxidants on Lactobacillus casei Cultures," Acta Scientiarum Polonorum. Technologia Alimentaria, Vol. 7, No. 4, 2008, pp. 39-51.

[34] S. Hekmat and G. Reid, "Survival of Lactobacillus reuteri RC-14 and Lactobacillus rhamnosus GR-1 in Milk," International Journal of Food Science \& Technology, Vol. 42, No. 5, 2007, pp. 615-619. doi:10.1111/j.1365-2621.2006.01292.x

[35] J. K. Lim, H. J. Kang, S. N. Kang and B. Y. Lee, "Antioxidant and Antimicrobial Activities of Various Solvent Fractions of Fine Ginseng Root," Food Science and Biotechnology, Vol. 18, No. 2, 2009, pp. 513-518.

[36] M. S. Y. Haddadin, "Effect of Olive Leaf Extracts on the Growth and Metabolism of Two Probiotic Bacteria of Intestinal Origin," Pakistan Journal of Nutrition, Vol. 9, No. 8, 2010, pp. 787-793. doi:10.3923/pjn.2010.787.793

[37] E. Medina, A. De Castro, C. Romero and M. Brenes, "Comparison of the Concentrations of Phenolic Compounds in Olive Oils and Other Plant Oils: Correlation with Antimicrobial Activity," Journal of Agricultural and Food Chemistry, Vol. 54, No. 14, 2006, pp. 4954-4961. doi:10.1021/jf0602267

[38] K. Kailasapathy and J. Chin, "Survival and Therapeutic Potential of Probiotic Organisms with Reference to Lactobacillus acidophilus and Bifidobacterium spp.," Immunology and Cell Biology, Vol. 78, No. 1, 2000, pp. 80-88. doi:10.1046/j.1440-1711.2000.00886.x

[39] I. Figueroa-González, G. Quijano, G. Ramírez and A. Cruz-Guerrero, "Probiotics and Prebiotics-Perspectives and Challenges," Journal of the Science of Food and Agriculture, Vol. 91, No. 8, 2011, pp. 1341-1348. doi:10.1002/jsfa.4367

[40] D. Wan, L. Jiao, H. Yang and S. Liu, "Structural Characterization and Immunological Activities of the WaterSoluble Oligosaccharides Isolated from the Panax Ginseng Roots," Planta, Vol. 235, No. 6, 2012, pp. 12891297. doi:10.1007/s00425-011-1574-x 